\title{
Cláusulas de jurisdicción y legislación aplicable en los contratos de endeudamiento externo de los Estados latinoamericanos
}

\author{
Por Jürgen Samtleben
}

\section{Introducción}

La deuda externa de América Latina, que hace diez años alcanzó 150 mil millones dólares, hoy ya ha superado la cifra astronómica de 400 mil millones dólares. ${ }^{1}$ Nadie puede dudar realmente que esta deuda externa, convertida en deuda eterna, no se podrá pagar nunca. Se espera una solución del problema por el lado político-económico, donde ya se discuten varios modelos. En el supuesto de que estas tentativas fracasen, se impone una solución jurídica, sea en sentido formalista - con inevitables consecuencias para la economía mundial - o sea de carácter equitativo. En este contexto, todo dependerá del tribunal que conozca del asunto y de la legislación que sea aplicada. He aquí un aspecto central del problema, que, en las negociaciones sobre la deuda externa, siempre ha sido objeto de controversias políticas y jurídicas.

\section{Los contratos de endeudamiento público externo}

La mayor parte de la deuda externa de América Latina es deuda del sector público, sobre todo préstamos de los bancos extranjeros a los gobiernos latinoamericanos o otras entidades estatales. Por eso conviene centrar la siguiente discusión en esta materia. Analizaremos primero los intereses y objetivos de los acreedores, para ocuparnos después de la situación de la parte deudora. Con una mirada puesta en algunos casos prácticos, terminaremos luego esta primera parte, que nos sirve de introducción a estos problemas.

\section{La posición de los acreedores}

El banco extranjero, como prestamista, tiene un objeto principal: asegurar el reembolso del crédito y el pago de los intereses. Por eso es lógico que quiera evitar que la ef ectivi-

1 Según las estadísticas de la CEPAL (Comisión Económica para América Latina y el Caribe). Para una visión de conjunto véase recientemente Romero Pérez, Jorge Enrique, "Deuda externa: otra cara de la crisis", Revista de Ciencias Juridicas, San José, núm.59, 1988, pp. 63-112. 
dad del crédito pueda ser afectada por modificaciones posteriores de la legislación del Estado deudor. Esta es la principal razón por la que, en estos contratos, se suele insertar cláusulas expresas sobre jurisdicción y legislación aplicable que tienden a garantizar la independencia del crédito de toda influencia de la parte deudora. A esto se suman razones de practicabilidad, que normalmente hacen aconsejable para el prestamista escoger la competencia de los tribunales y legislación de su propio Estado. Por tales motivos estas cláusulas se cuentan entre las más importantes del contrato. ${ }^{2}$

En la práctica del financiamiento internacional ${ }^{3}$ dominan las cláusulas que establecen la competencia de los tribunales de Nueva York o Londres y la aplicación de la respectiva legislación. Esto tiene que ver con el papel de estos lugares como centros del mercado financiero internacional, donde se encuentra la sede de los bancos más importantes. Del mismo modo se suele acordar la competencia de los tribunales y leyes de otros Estados, si el banco acreedor tiene allí su sede. Generalmente, se exige del Estado deudor también una renuncia previa a su inmunidad soberana. Así estas cláusulas tienen un aspecto uniforme como una golden rule, que un escritor mexicano explica así: "He who has the gold, makes the rule ${ }^{4}$ De hecho se trata aquí de un cartel de condiciones por parte de los bancos acreedores.

\section{La posición de los deudores}

La situación de los Estados deudores es menos homogénea. Es verdad que de vez en cuando surge la idea de un posible cartel de deudores. Pero, en la realidad, las necesidades económicas de estos países son tan diferentes que no se logra una acción común que pasa de la retórica. Las moratorias se declaran unilateralmente y cada Estado busca un arreglo con los acreedores por su propia cuenta. En la urgencia de obtener fresh money se aceptan todas las cláusulas que los bancos proponen, incluso las relativas a la jurisdicción y legislación aplicable.

En cambio, la doctrina y práctica de los países latinoamericanos muestra que siempre

2 Cf. en Sovereign Lending: Managing Legal Risk, ed. Gruson, Michael, y Reisner, Ralph, London, Euromoney Publications, 1984, pp. 29 ss., 51 ss., 69 ss.; Wood, Philip, "External Governing Law - Either a Fortress or a Paper-House", International Financial Law Review, London, Euromoney Publications, July 1982, pp. 11-14; Śarčević, Petar, "Rechtsfragen der Umschuldung", Zeitschrift für das gesamte Kreditwesen, Frankfurt, 1985, pp. 53-56. En el mismo sentido el "Report of the Monetary Committee of the International Law Association to the Seoul Conference 1986", publicado por Hugo Hahn, en Foreign Debts in the Present and a New International Economic Order, ed. Dicke, Detlev, Fribourg (Suiza), University Press, 1986, pp. 97 ss., 103 y 105 .

3 Wood, Philip, Law and Practice of International Finance, London, Sweet \& Maxwell, 1980, pp. 22 ss., 58 ss., 110 s.; Venkatachari, K., "The Eurocurrency Loan: Role and Content of the Contract ", en Sovereign Borrowers, Guidelines on Legal Negotiations with Commercial Lenders, ed. Kalderén, Lars, y Siddiqi, Qamar S., London, Butterworth, 1984, pp. 73 ss., 101 ss.; Hinsch, Christian, y Horn, Norbert, Das Vertragsrecht der internationalen Konsortialkredite und Projektfinanzierungen, Berlin y New York, de Gruyter, 1985, pp. 151-155.

4 Vásquez Pando, Fernando A., "The Mexican Debt Crisis in Perspektive: Faulty Legal Structures and Aftershocks", Texas International Law Journal, vol. XXIII, 1988, pp. 171 ss., 204. 
hubo una fuerte oposición en contra de tales cláusulas, basadas en una dudosa autonomía de las partes. ${ }^{5}$ Esta tendencia se hace resaltar especialmente en las relaciones entre el Estado soberano y las empresas extranjeras. En este contexto hay que recordar la gran influencia que, hasta nuestros días, tiene la doctrina Calvo, que exige la sumisión de los extranjeros a la jurisdicción y legislación del país en que efectúan actividades económicas o con cuyo gobierno entran en relaciones contractuales. ${ }^{6}$ Otra fuente de influencia es la doctrina Drago, según la cual la deuda pública resulta de la actividad soberana del Estado y está su jeta a su legislación y jurisdicción exclusiva, lo que excluye el cobro compulsivo por parte de otros Estados. ${ }^{7}$ Finalmente la Convención Interamericana sobre Competencia en la Esfera Internacional, suscrita en La Paz en 1984, sólo admite en su art. 1 lit. D la prórroga de la competencia internacional, "siempre y cuando tal competencia no haya sido establecida en forma abusiva". Esta disposición también puede servir de argumento para cuestionar la validez de las cláusulas de jurisdicción en los contratos financieros, porque éstas sólo obran en favor de los bancos extranjeros y por eso pueden considerarse abusivas. ${ }^{8}$

\section{Casos prácticos}

Durante mucho tiempo esta problemática ha sido subestimada porque en la práctica los conflictos entre los acreedores y el Estado deudor no se llevaron al terreno judicial, sino que eran objeto de negociaciones. No obstante, los bancos siempre han insistido en estas cláusulas contractuales para fortalecer su poder de negociación. ${ }^{9}$ Pero en los últimos años han surgido en la jurisprudencia norteamericana varios casos que se refieren a la deuda externa de los Estados latinoamericanos.

Así, en Libra Bank Ltd. v. Banco Nacional de Costa Rica y en el más famoso caso Allied Bank International v. Banco Crédito Agrícola de Cartago se trataba de demandas contra bancos estatales costarricenses, que, como consecuencia de un decreto de emergencia del Gobierno de Costa Rica, estaban impedidos para cumplir sus obligacio-

5 Cf. en general Samtleben, Jürgen, "Teixeira de Freitas e a autonomia das partes no direito internacional privado latino-americano", Scientia Iuridica, Braga, Livraria Cruz, t. XXXIII, 1984, pp. 344 ss., 357 ss. = Revista de Informação Legislativa, Brasília, Senado Federal, núm. 85, 1985, pp. 257 ss., 268 ss.

6 Ver Roffe, Pedro, "Calvo y su vigencia en América Latina", Revista de Derecho Industrial, Buenos Aires, Depalma, año VI, 1984, pp. 353-384; Leavy, James, "The Calvo Doctrine in Latin American Loans", International Financial Law Review, Oct. 1985, pp. 31-34.

7 Drago, Luis M., "Les emprunts d'État et leurs rapports avec la politique internationale", Revue générale de droit international public, Paris, t.XIV, 1907, pp. 251-287; IDEM, "State Loans in Their Relation to International Policy", The American Journal of International Law, vol. I, 1907, pp. 692-726; sobre el origen histórico de esta doctrina ver infra, III 8. Cf. también Segal, Rubén, y Pinto, Mónica, "Inviabilidad del cobro compulsivo de deudas de un Estado por otro y la moral económica internacional", La Ley, Buenos Aires, $\mathrm{t}$. 1984-C, pp. 1227-1231.

8 Vázquez Pando, supra nota 4, p. 206.

9 Wood, supra nota 3, p. 58; Bosch, Ulrich, "Vertragliche Regelungen in internationalen Kreditverträgen als risikopolitisches Instrument", en Internationales Bankgeschäft, ed. Krümmel, Hans-Jacob, Berlin, Duncker \& Humblot, 1985, pp. 117 ss., 155. 
nes pactadas en moneda extranjera. ${ }^{10}$ Sin entrar aquí en detalles, hay que resaltar que estas demandas en el foro contractual de Nueva York prosperaron sobre la base del Derecho neoyorquino aplicable, rechazándose la excepción de inmunidad y la defensa basada en la actitud soberana del Estado costarricense. ${ }^{11}$ En cambio, en Braka v. Bancomer y otros casos similares, donde se trataba de depósitos en bancos mexicanos en moneda extranjera que poco antes de la nacionalización de la banca mexicana habían sido convertidos en pesos mexicanos, la jurisprudencia norteamericana ha aplicado la doctrina de act of state para reconocer la validez de esta conversión dentro del propio territorio mexicano, sin excluir una eventual responsabilidad del banco deudor por actos anteriores a esta conversión. ${ }^{12}$ Finalmente, hay que mencionar el caso Nordic Asia Ltd. v. Corporación Venezolana de Fomento, en el cual la actora logró el reembolso total del crédito garantizado por la demandada, una institución del sector público venezolano, por medio de un embargo preventivo de sus cuentas bancarias en Nueva York. ${ }^{13}$

Sea cual fuera en el fondo la solución justa y adecuada de estas controversias, los casos mencionados evidencian que los tribunales en los países acreedores pueden ejercer la jurisdicción sobre estas demandas a base de su propio Derecho, sin preocuparse de los argumentos que se hacen valer en los países deudores para atribuirles la jurisdicción exclusiva. De ahí resulta que estos argumentos sólo pueden imponerse por medio de una

10 Libra Bank Ltd. v. Banco Nacional de Costa Rica, 676 F.2d 47 (2d Cir. 1982); 570 F.Supp. 870 (S.D.N.Y. 1983); Allied Bank International v. Banco Crédito Agrícola de Cartago, 566 F.Supp. 1440 (S.D.N.Y. 1983); 23 International Legal Materials 742 (1984) (2d Cir. 1984), rev'd, 757 F.2d 516 (1985), cert.dismissed, 473 U.S. 934.

11 Cf. los comentarios: Barist, Jeff rey, "Recent Developments Concerning the 'Act of Stater Doctrine: The Allied Bank Decision", Revue de droit des affaires internationales, Paris, 1985, pp. 851-857; Cárdenas, Emilio J., "El caso 'Allied Bank International: Al final, lo previsible", La Ley, Buenos Aires, t. 1985-C, pp. 1176-1179; Hahn, Hugo, "Zahlungsmoratorium außerhalb des Verbotsstaates ist kein 'Act of State“, Zeitschrift für das gesamte Kreditwesen, Frankfurt, 1985, pp. 892-894, 934-948; Quale, Andrew C., Campbell, Barry R., y Herzstein, Robert E., "Allied Bank's Effect on International Lending", International Financial Law Review, Aug. 1985, pp. 26-31; Bainbridge, Stephen, "Comity and Sovereign Litigation: A Bankruptcy Analogy", Maryland Journal of International Law and Trade, vol. X, 1986, pp. 1-47; Carreau, Dominique, "La nouvelle décision américaine Allied Bank International ou un retour ambigu à la protection juridique des créanciers dans la procédure des rééchelonnements de dettes internationales ", Journal du droit international, Paris, año CXIII, 1986, pp. 123-125; Furnish, Dale Beck, "El derecho privado de los Estados Unidos frente a la deuda externa ", Revista Peruana de Derecho Internacional, t. XXXVIII, 1986, pp. 93-116 = Boletin Mexicano de Derecho Comparado, UNAM, núm.58, 1987, pp. 31-55; Rendell, Robert S., "The Allied Bank Case and Its Aftermath", The International Lawyer, ABA, Chicago, vol. XX, 1986, pp. 819-828; Sklar, Ruben, "Renegotiation of External Debt: The Allied Bank Case and the Chapter 11 Analogy“, The University of Miami Inter-American Law Review, vol. XVII, 1985/86, pp. 59-90.

12 Braka v. Bancomer, 762 F. 2d 222 (2d Cir. 1985); Callejo v. Bancomer, 764 F. 2d 1101 (5th Cir. 1985); Riedel v. Banam SA, 792 F. 2d 587 (6th Cir. 1986); Grass v. Crédito Mexicano SA, 797 F. 2d 220 (5th Cir. 1986); West v. Multibanco Comermex SA, 807 F. 2d 820 (9th Cir. 1987). Cf. sobre casos anteriores Morgan, Robert L., y otros, "Legal Issues Arising from the Mexican Economic Crisis", Vanderbilt Journal of Transnational Law, vol. XVII, 1984, pp. 367 ss., 410 s., 447 ss.; Rendell, Robert S., "Mexican Currency Claim Dismissed", International Financial Law Review, Sept. 1983, p. 40. Cf. infra, nota 95.

13 Cf. sobre este caso Brown, Christopher R., "How to Be Paid on a Defaulting Loan", International Financial Law Review, April 1983, pp. 10-12. Ver también el caso Italian International Bank Ltd. v. Banco Industrial de Venezuela, No. 83-5288, slip op. (S.D.N.Y. 1984), y el relato en International Financial Law Review, Feb. 1984, p.3. Cf. infra, nota 87 . 
prohibición legal que veda a la propia administración aceptar tales cláusulas, que puedan conducir a un proceso judicial en el extranjero. Vamos a ver en seguida como se refleja esta tendencia en el Derecho de los países latinoamericanos.

\section{La posición de los países latinoamericanos}

El crecimiento del mercado financiero internacional ha producido en muchos países normas legales que regulan las facultades de la administración y las condiciones bajo las cuales puede obligarse en este sector. ${ }^{14}$ Pero en ninguna región del mundo las cosas han alcanzado un aspecto tan dramático como en América Latina. Aquí encontramos en lucha una posición internacionalista, que por adaptación o por necesidad sigue todas las exigencias de la banca internacional, y una posición nacionalista, que reclama invariablemente el derecho soberano e ilimitado del Estado de controlar todas las condiciones y consecuencias de la deuda pública. Eso lo queremos demostrar con un relato de los acontecimientos más recientes en estos países.

\section{Argentina}

En la Argentina, la posición internacionalista en los años setenta encontró su expresión en el art. 7 de la ley 20548 del 6 de noviembre de 1973, modificador del art. 48 de la ley 16432 del 1 de diciembre de 1961, que en relación con los préstamos internacionales ahora dice asi:

"El Poder Ejecutivo queda asimismo facultado para prestar la garantía de la Nación, con carácter accesorio o principal, a obligaciones que con las finalidades y bajo los requisitos mencionados asuman entidades públicas y privadas, así para someter eventuales controversias con personas extranjeras a jueces de otras jurisdicciones, tribunales arbitrales con dirimente imparcialmente designado o a la Corte Internacional de Justicia de La Haya."

Esta disposición ya en el Congreso, donde se justificaba abiertamente con la necesaria "operatividad en la captación del crédito externo", había tropezado con una fuerte oposición. ${ }^{15}$ Esta oposición se basaba político y jurídicamente en el art. 100 de la Constitución, conforme al cual "los asuntos en que la Nación sea parte" corresponden a la Corte Suprema y a los tribunales inferiores de la Nación, una norma constitucional que

14 Cf. para España Ojeda Marín, Alfonso, Créditos y préstamos exteriores al sector público español, Madrid, 1985; también el Seminario sobre régimen jurídico de los préstamos sindicados internacionales, ed. Conse jo Superior Bancario, Madrid, 1980; para otros países p.ej. Schroeder-Hohenwarth, Hinrich, Kreditaufnahme afrikanischer Staaten im Ausland, Hamburg y Frankfurt, 1974; Meyer, Niti Klaus, Legal Aspects of Eurocurrency Credits and Foreign Lending in Thailand, Freiburg (Suiza), Universitätsverlag, 1983.

15 Cf. Pasini Costadoat, Emilio, "La prórroga de la competencia a favor de árbitros y tribunales extranjeros", La Ley, Buenos Aires, t. 1976-C, pp. 599 ss., 601. 
ya ha dado lugar a muchas controversias en la doctrina argentina. ${ }^{16}$ En la práctica, el Gobierno y las entidades estatales argentinas en numerosos casos han aceptado la jurisdicción y legislación extranjeras en contratos financieros con la banca internacional. ${ }^{17}$ Los argumentos en contra de esta práctica sólo raramente han sido aceptados por los órganos oficiales del Estado hasta que, de pronto, culminaron en un proceso famoso que tiene toda la apariencia de una pieza teatral surrealista. ${ }^{18}$

Era en las postrimerías del régimen militar, el cual en el año 1983, poco antes de las elecciones para un Gobierno civil, trataba de negociar la conversión de la deuda externa. Las conversaciones con los acreedores y el Fondo Monetario Internacional en Nueva York resultaron en un "modelo de contrato de refinanciación garantizado", que preveía la sumisión irrevocable de la parte deudora a los tribunales de Nueva York o de la Argentina, a elección de los acreedores. ${ }^{19}$ Esta noticia llegó por el éter hasta la Patagonia al juez federal Pinto Kramer, actuando en Rio Gallegos en el extremo sur de la Argentina. Este juez no tardó en pronunciar contra su propio Gobierno una "prohibición de innovar" con el mandamiento estricto de no firmar tal cláusula en los contratos de refinanciación. El presidente del Banco Central argentino se vió obligado a volver a Buenos Aires, pero fué detenido allí en el propio aeropuerto y trasladado a la penitenciaria de Rio Gallegos, donde fué interrogado por Pinto Kramer. La actuación del juez de Rio Gallegos luego tocó a su fin con dos sentencias de la Cámara Federal de Apelaciónes de Comodoro Rivadavia, que la declaró improcedente y negó la competencia del juez. ${ }^{20}$ Pero, entretanto, las negociaciones sobre la conversión de la deuda externa ya habían fracasado.

Esta conversión sólo la logró el Gobierno civil dos años más tarde. ${ }^{21}$ Desde entonces, todos los contratos de refinanciación incluyen las cláusulas incriminadas, a pesar de que voces críticas siguen cuestionando su conveniencia y legitimidad. ${ }^{22}$

16 Ver sobre los diferentes opiniones Ramayo, Raúl Alberto, "El art.100 de la Constitución Nacional y la Nación como parte ante los tribunales de otro país", La Ley, Buenos Aires, t. 1976-B, pp. 671-678.

17 Ver los ejemplos en Goldschmidt, Werner, "Transactions Between States and Public Firms and Foreign Private Firms, A Methodological Study", Recueil des Cours, t. CXXXVI (1972-II), pp. 203 ss., 263 ss.; Boggiano, Antonio, "International Contracts in Argentina", Rabels Zeitschrift für ausländisches und internationales Privatrecht, Tübingen, año XLVII, 1983, pp. 431 ss., 471 s.

18 Para los detalles ver Samtleben, Jürgen, "'Der Kampf ums Forum' - Ein Gefecht in Patagonien", Rabels Zeitschrift für ausländisches und internationales Privatrecht, año XLVII, 1983, pp. 738-743.

19 Decretos 2408 y 2410 del 15 de septiembre de 1983, ADLA t. XLIII-D, pp. $4187-4277$ (ver la sección 12 del contrato).

20 Cámara Federal de Apelaciones de Comodoro Rivadavia, 8 de octubre de 1983, La Ley, Buenos Aires, t. 1983-D, pp. 600 y $610=$ El Derecho, Buenos Aires, t. CVI, 1984, pp. 276 y 284.

21 Decreto 1579 del 22 de agosto de 1985, Boletin Oficial del 26 de agosto de 1985. Sobre los acuerdos de refinanciación de 1985 y 1987 ver de la Cruz, Andrés, "A Case Study in Third World Debt: Argentina", The International Lawyer, vol. XXII, 1988, pp. 643 ss., 656 ss., 660.

22 Un buen resumen de los argumentos en pro y en contra se halla en Cárdenas, Emilio J., "Argentina Before Foreign Courts", International Financial Law Review, April 1984, pp. 22-25; ver últimamente Rizzi Romano, Alf redo H., "La 'doctrina Calvo y las empresas multinacionales (Renuncia de jurisdicción en el pago de la deuda pública)", La Ley, Buenos Aires, t. 1986-E, pp. 901 ss., 903: "Desde el punto de vista político-jurídico un Estado Nacional no puede, sin grave mengua de su soberanía, renunciar a su jurisdicción originaria..." 


\section{Brasil}

En el Brasil, la materia está regulada en el Decreto-Lei 1312 del 15 de febrero de 1974, cuyo art. 11 reza:

"O Tesouro Nacional contratando diretamente ou por intermédio de agente financeiro poderá aceitar as cláusulas e condições usuais nas operações com organismos financiadores internacionais; sendo válido o compromisso geral e antecipado de dirimir por arbitramento todas as dúvidas e controvérsias dos respectivos contratos. "23 $^{23}$

Salta a la vista la diferencia de esta norma comparándola con el Derecho argentino, porque sólo se refiere a la solución de las controversias por arbitraje. Esto se justifica por la opinión generalizada en el Brasil de que el Estado como soberano no puede someterse a la jurisdicción de otros Estados. El fundamento de esta opinión lo encontramos también en la Constitución brasileña, que establece la competencia de los tribunales federales para las "causas em que a União, entidade autárquica ou empresa pública federal forem interessadas «. ${ }^{24}$ En cambio, este precepto constitucional no se considera obstáculo para que el Estado se someta a un procedimiento arbitral, ${ }^{25}$ lo que explica que el gobierno del Brasil en varias oportunidades ha aceptado cláusulas arbitrales en contratos financieros de carácter internacional, visando la solución de controversias por árbitros en el extranjero. ${ }^{26}$

Como en la Argentina, también en el Brasil la renegociación de la deuda externa en el año 1983 desencadenó una serie de discusiones públicas. ${ }^{27}$ Abiertamente se criticaron las

23 Una norma casi idéntica ya se encontraba en la Lei 1628 de 1952, art.23, limitada a las actividades del Banco Nacional do Desenvolvimento Econômico; ver también la Lei 5662 de 1972, art. $5 \S 1$.

24 Art. 125 de la Constitución de 1969, y ahora art. 109 de la Constitución de 1988. Ver en detalle Dolinger, Jacob, "A imunidade jurisdicional dos Estados", Revista Forense, Rio de Janeiro, vol. 277, 1982, pp. 53 ss., 75 ss. = Revista de Informação Legislativa, Brasília, núm.76, 1982, pp. 5 ss., 54 ss., citando también el Decreto 15.783 de 1922, art. 775, § 1 e). En contra de esta opinión Magalhães, José Carlos de, "Do Estado na arbitragem privada", Revista de Informação Legislativa, núm.86, 1985, pp. 125 ss., 134 ss.

25 Ver la jurisprudencia brasileña citada en Samtleben, Jürgen, "Arbitration in Brazil ", The University of Miami Inter-American Law Review, vol. XVIII, 1986/87, p.1 ss., 8. También en foros internacionales Brasil ha defendido la posición que el Estado sólo puede someterse a tribunales arbitrales, pero no a la jurisdicción de otros Estados; así en la Conferencia de Roma de 1952 sobre derecho privado aéreo, según Romang. Werner, Zuständigkeit und Vollstreckbarkeit im internationalen und schweizerischen Luftprivatrecht, Winterthur (Suiza), 1958, p. 150.

26 Cf. Dolinger, Jacob, "Bônus brasileiros no mercado financeiro alemão, "Revista Forense, vol. 244, 1973, pp. 373 ss., 379 s.; Clare, J. Anthony, "Enforcement of the Arbitration Clause in Brazilian Loan Agreements", International Financial Law Review, Nov. 1982, pp. 18-23; Pinheiro Neto, J. M., "Brazil's Restructuring: The Legal Issues", ibidem, Aug. 1983, pp. 5 s.; Delaume, Georges R., "The ICSID and the Banker", ibidem, Oct. 1983, pp. 9 ss., 13. La insistencia del Brasil en esta cláusula causó la retirada de un grupo de grandes bancos neoyorquinos de un crédito sindicado en 1977; ver Quale, Andrew C., "Legal Aspects of Lending in Latin America", en Financing Development in Latin America, ed. Garcia-Zamor, Jean-Claude, y Sutin, Stewart E., New York, Praeger, 1980, pp. 286 ss., 299; Kahale, Georges S. III, "State Loan Transactions: Foreign Law Restrictions on Waiver of Immunity and Submissions to Jurisdiction", The Business Lawyer, ABA, Chicago, vol. XXXVII, 1981/82, pp. 1549 ss., 1557 ss., con más detalles sobre la práctica. 
cláusulas del acuerdo de refinanciación que establecían la sumisión de la República al arbitraje en el extranjero y la renuncia a la inmunidad, aceptando además para las obligaciones del Banco Central la competencia de los tribunales y la aplicación de la ley de Nueva York, cláusulas que en el Senado del Brasil fueron calificadas como ofensa a la soberanía nacional. ${ }^{28}$ Por otro lado, juristas de renombre trataban de defender estas cláusulas, ${ }^{29}$ advirtiendo que, según el Derecho internacional privado brasileño, los contratos se rigen por la ley del lugar de la celebración, que, en este caso, era Nueva York. ${ }^{30}$ En tal clima de tensión, dos expedientes captaron la atención pública. La representación de la abogacía brasileña, la "Ordem de Advogados do Brasil" (OAB), formalmente solicitó al Procurador General de la República entablar una acción de inconstitucionalidad respecto del acuerdo de refinanciación, lo que éste rehusó. ${ }^{31} \mathrm{Al}$ mismo tiempo, un periodista en Rio de Janeiro, Hélio Fernandes Filho, presentó ante la justicia federal una "ação popular" en contra del mencionado acuerdo. Esta acción fué desestimada en primera instancia dos años más tarde, en enero de 1985, por ser insuficientemente fundada. ${ }^{32}$

En aquel año, el Brasil volvió a la democracia, después de largos años del régimen militar. El gobierno civil de la Nova República declaró en varias oportunidades que no aceptaría ninguna cláusula en relación con la deuda externa que infringiera la soberanía del Brasil. ${ }^{33}$ Pero las prolongadas negociaciones con los acreedores - después de una moratoria unilateralmente declarada por el Brasil - finalmente en junio de 1988 se concretaron en un plan de refinanciación, que contiene las mismas cláusulas que el acuerdo de $1983 .^{34}$

27 Ver el panorama general en Zimbler, Brian L., "Debtor State Law and Default: Enforcement of Foreign Loan Agreements in Brazilian Courts", The University of Miami Inter-American Law Review, vol. XVII, $1985 / 86$, pp. 509-576.

28 Ibidem, pp. 514 ss., 520, 524 ss.; cf. también Lopes, Jair Leonardo, "A solução é de ordem política", en F.M.I. e soberania nacional, Belo Horizonte, 1984, pp. 43-50.

29 Cf. Huck, Hermes Marcelo, "Contratos internacionais de financiamento: A lei aplicável ", Revista de Direito Mercantil, São Paulo, núm. 53, 1984, pp. 81-87; Wald, Arnoldo, "A renegociação da dívida externa e o respeito à soberania nacional“, ibidem, núm. 56, 1984, pp. 35-41.

30 Lei de Introdução (1942) a o Código Civil, art. 9. En este contexto, ver la Portaria do Ministério da Fazenda núm. 296 del 6/9/1975, según la cual los contratos de este tipo deben ser firmados en la Capital de la República, y sólo excepcionalmente en el exterior; cf. Salles, Ricardo, "Alguns aspectos jurídicos dos contratos internacionais de mútuo", Revista Forense, vol. 256, 1976, p. 37.

31 Despacho do Procurador-Geral da República, 17/1/1984, PGR No.055210/83, en Diário da Justiça, Brasília, 19/1/1984, sobre la base de un extenso Parecer do Procurador-Geral da Fazenda Nacional, 5/11/1983, publicado en Diário Oficial, 10/1/1984, Seção I, pp. 413-432; cf. Zimbler, supra nota 27, pp. 568 s.

32 6a Vara Federal, Rio de Janeiro, 11/1/1985, Proc.No.5418100/83; cf. Zimbler, supra nota 27, pp. 569 ss.

33 Según informaciones de prensa en $O$ Globo del 3 de julio de 1985 y en Jornal do Brasil del 17 de febrero de 1986; cf. también Russomano, Nailê, "Dívida externa do Brasil e a argüição de sua inconstitucionalidade (Tese aprovada no VIII Congresso Brasileiro de Direito Constitucional)", Revista de Informação Legislativa, núm.96, 1987, pp. 195-200; sobre las negociaciones con los bancos Bacha, Edmar L., "Entre a acomodação e o confronto: os dilemas da renegociação da dívida externa brasileira, 1983-1987 ", Revista de economia política, São Paulo, núm. 30, 1988, pp. 49 ss., 58, 62.

34 Plan de refinanciación del 22 de junio de 1988, firmado en Nueva York el 22 de septiembre de 1988. Sobre los efectos jurídicos de la moratoria de 1987 ver Albino, Fernando, "Brazil says, 'No more ", International Financial Law Review, June 1987, pp. 21-23. 


\section{Colombia}

Colombia siempre ha sido considerado un país de línea dura en relación con la doctrina Calvo. ${ }^{35}$ Esto se ve claramente en las disposiciones legales que regulan la contratación por parte de la Nación y sus entidades descentralizadas. Así tanto el Decreto 150 de 1976 como el hoy vigente Decreto 222 de 1983 establecen que todos los contratos que celebre la Nación con personas extranjeras están sujetos a la ley y jurisdicción colombiana, sólo admitiéndose una sumisión a árbitros nacionales. ${ }^{36}$ Pero ante la necesidad aparente del crédito externo, el Decreto 150 de 1976 abrió para los empréstitos internacionales una excepción en favor del arbitraje en el extranjero, que fué declarada luego inconstitucional por la Corte Suprema. ${ }^{37}$

Esta decisión de la Corte, que se fundó en el poder jurisdiccional absoluto del Estado dentro del territorio, que sólo se podría limitar por tratados internacionales, provocó dos reacciones. Por un lado, el Gobierno colombiano se adhirió al la Convención de Nueva York sobre el reconocimiento y la ejecución de las sentencias arbitrales extranjeras de $1958 .^{38}$ Por otro lado, las leyes posteriores en que el Congreso autorizó al Gobierno para realizar operaciones de crédito y refinanciación de la deuda externa, permitieron expresamente que "los convenios o contratos que se celebren para ser ejecutados en el exterior se someterán, en cuanto a legislación y jurisdicción, a lo que en los mismos se pacte ". ${ }^{39}$ Sin embargo, el alcance tanto de la adesión a la Convención de Nueva York como de las mencionadas autorizaciones legales resultó dudoso, teniéndo en cuenta el fallo supremo de 1976. En la práctica, la administración se negó a aceptar cláusulas de jurisdicción o arbitraje extranjero en contratos de financiación internacionales, insistiendo en la sumisión a la ley y jurisdicción colombiana. ${ }^{40}$

Como en Argentina y Brasil, también en Colombia las cosas se agravaron en el año

35 Leavy, supra nota 6, pp. 31 y 33, citando el art. 11 de la Constitución. En materia de inversiones extranjeras, ver la sentencia de la Corte Suprema del 6 de diciembre de 1984, Foro Colombiano, Bogotá, t. XXXII, 1985 , pp. 147 ss.

36 Decreto 150 del 27 de enero de 1976, arts. 63, 66 s.; Decreto 222 del 2 de febrero de 1983, arts. 74, 76 s. Sobre el Estado colombiano como parte en juicios arbitrales ver Samtleben, Jürgen, "Schiedsgerichtsbarkeit in den Andenpaktstaaten", Recht der internationalen Wirtschaft, Heidelberg, año XXX, 1984, pp. 600 ss., 867 s.

37 Sentencia de la Corte Suprema del 26 de agosto de 1976, Foro Colombiano, t. XV, 1976, pp. 381 ss., respecto del art. 115 del Decreto 150 de 1976. Comentario en Caicedo Castilla, José Joaquín, "La cláusula compromisoria en los contratos de empréstito externo", Revista de Derecho Mercantil, Bogotá, año IV, 1979, pp. 185 ss., 189 ss., 201 ss.

38 Aprobado por Ley 37 del 6 de julio de 1979; sobre la adesión y los problemas de aplicación ver Samtleben, supra nota 36, pp. 600 s.; Holguín Holguín, Carlos, "El concepto de orden público en la Convención de Nueva York y otros comentarios", Revista Cámara de Comercio de Bogotá, núm. 58, 1985, pp. 129 ss., 135.

39 Ley 63 de 1978, art. 5; Ley 25 de 1980, art. 8; Ley 74 de 1981, art. 15. Para una interpretación restrictiva ver Linares Cantillo, Alejandro, "La ley aplicable a la celebración, validez y perfeccionamiento de los contratos de empréstito externo de la Nación y sus entidades descentralizadas", Revista de Derecho Privado, Bogotá, vol. I, 1987, núm.2, pp. 129 ss., 133 n.9.

40 Leavy, supra nota 6, pp. 33 s.; Quale, supra nota 26, pp. 298 s. Ver p.ej. el contrato de empréstito entre la Nación Colombiana y la sociedad inglesa Balfour Beatty Power Construction Ltd. del 18 de diciembre de 1981 (cláusula 8a), Diario Oficial, núm. 35961, del 9 de marzo de 1982. 
1983, porque su posición inflexible le dificultaba el acceso al crédito externo que el país necesitaba. En esta situación, el Decreto 222 del 2 de febrero de 1983 sobre la contratación administrativa trató de abrir una brecha para los préstamos internacionales con su art. 239, que distingue entre la celebración y la ejecución del contrato:

"En todo caso, la celebración de los contratos de empréstito se someterá a la ley colombiana y a la jurisdicción de los jueces y tribunales colombianos. Los contratos celebrados en el exterior que deban ejecutarse en el país, se regirán por la ley colombiana.

La ejecución de los contratos de empréstito que deba verificarse en el exterior, podrá someterse, en cuanto a la ley y jurisdicción, a lo que en ellos se pacte.

Podrá estipularse la cláusula compromisoria con el fin de someter a la decisión de árbitros las controversias que se susciten durante la ejecución del contrato o en relación con la misma."

Pero esta norma, que permite pactar la ley y jurisdicción extranjera para la ejecución del contrato, cuando ésta se verifica en el exterior, y también un procedimiento arbitral en el extranjero, planteaba arduas problemas de interpretación. ${ }^{41}$ Antes de firmar el primer contrato de crédito en que se pactó la ley y jurisdicción inglesa, los bancos acreedores exigieron un nuevo decreto interpretativo sobre el lugar de ejecución, siendo ahora suficiente que la entrega del capital o el pago des deudor deba realizarse en el extranjero. ${ }^{42}$ Otros bancos lograron una sumisión a la ley y jurisdicción extranjera sin limitación al aspecto de la ejecución, valiéndose de la legislación anterior al Decreto 222.43 Finalmente, para calmar las inquietudes de los bancos extranjeros sobre la situación legal, el Gobierno promovió una reforma legislativa, autorizando el Consejo de Estado para dictaminar sobre la validez de cada contrato de crédito externo en particular. ${ }^{44}$

En esas circunstancias, una nueva decisión de la Corte Suprema estalló como una bomba. ${ }^{45}$ Por ocasión de los tristes eventos en las zonas afectadas por la actividad volcánica del Nevado del Ruíz, un decreto de emergencia había permitido la captación de recursos extranjeros, con la posibilidad de someter la ejecución de los respectivos contratos de empréstito a la ley y jurisdicción extranjeras. ${ }^{46}$ Esta autorización luego fué declarada in-

41 Ver Leavy, James, "Legal Memorandum: Colombia", Lawyer of the Americas, University of Miami, vol. XV, 1983/84, pp. 421 ss., 424 s.; IDEM, "Colombian Decree Confuses Issues in Syndicated Loans", International Financial Law Review, March 1984, pp. 47 s.; IDEM, "Business Not Quite as Usual", ibidem, Oct. 1984 , pp. $12 \mathrm{~s}$.

42 Decreto 2875 del 13 de octubre de 1983, art. 2. Ver Leavy, "Colombian Decre . .", supra nota 41; Slaughter \& May, "English Law for Colombia", International Financial Law Review, Jan. 1984, p. 10; cf. también Linares Cantillo, supra nota 39, p. 138 n.30, sobre la actitud de los bancos extranjeros.

43 Cf. Cavelier y otros, "Legal Ingenuity in Colombian Loans", International Financial Law Review, Jan. 1985, p. 5; ver las leyes citadas, supra, nota 39.

44 Ley 55 del 18 de junio de 1985, art. 59. Ver Leavy, James, "Decree 222 and Foreign Law", International Financial Law Review, Oct. 1985, p. 48; IDEM, "Colombie, Actualités juridique, fiscale et financière", Revue de droit des affaires internationales, Paris, 1985, pp. 985 ss., 988. Cf. infra, nota 48.

45 Sentencia de la Corte Suprema del 20 de marzo de 1986, Foro colombiano, t. XXXIV, 1986, pp. 331 ss.; también en Diritto del commercio internazionale, Milano, 1987, pp. 650 ss., con nota crítica de Antonio Crivellaro.

46 Decreto 3614 del 10 de diciembre de 1985, art. 3. 
constitucional por la Corte Suprema, poniendo en duda el estado legal de todos los contratos de crédito externo, lo que causó gran perturbación en los círculos bancarios. ${ }^{47} \mathrm{El}$ Consejo de Estado, en un dictamen sobre un contrato entre el Estado colombiano y un sindicato de bancos extranjeros, mantuvo la postura de que el fallo de la Corte Suprema en nada afectaría la autorización general contenida en el Decreto 222 de 1983.48 Esta opinión poco después fué corroborada por una otra decisión de la propia Corte Suprema, dejando en claro que el Decreto 222 sólo autoriza el pacto de la ley y jurisdicción extranjeras en relación con la ejecución de los contratos en el exterior, lo que no está vedado por la Constitución..$^{49}$ Con esto el Tribunal ha mostrado finalmente una salida a los bancos, porque éstos pueden determinar libremente el lugar de ejecución de los contratos de empréstito. ${ }^{50}$

\section{Chile}

En Chile, la posición nacionalista encontró su rotunda afirmación en la Declaración Presidencial del 9 de noviembre de 1971, del presidente constitucional Salvador Allende, sobre la renegociación de la deuda externa. Este documento no de jó ninguna duda de que la refinanciación de la deuda externa no podría realizarse sino bajo el control del Derecho chileno. ${ }^{51}$

Sin embargo, esta posición fué terminantemente superada con la toma del poder por el Gobierno militar en 1973, con su abierta inclinación para el capital extranjero. Así, el

47 Supra, nota 45. Ver los comentarios de Hernández M., Héctor, "Se está violando la Constitución", El tiempo del 22 de marzo de 1986; Leavy, James, "Court puts Foreign Loans in Danger", International Financial Law Review, July 1986, pp. 7 s.; Arenas, Ismael Enrique, "La Corte podrá dejar el país sin crédito externo", El tiempo del 11 de julio de 1986.

48 Dictamen del Consejo de Estado del 3 de junio de 1986, Foro Colombiano, t. XXXV, 1986, pp. 58 ss., sobre un empréstito jumbo de mil millones dólares. Ver el salvamento de voto del conse jero Humberto Mora Ose jo, ibidem, pp. 63 ss., 65: ". . la soberanía del país queda supeditada a los intereses extranjeros."

49 Sentencia de la Corte Suprema del 30 de octubre de 1986, Foro Colombiano, t. XXXVI, 1987, pp. 44 ss., sobre la base de los argumentos presentados en el proceso a favor de la constitucionalidad y necesidad de la norma en cuestión, ibidem, t. XXXV, 1986, pp. 15 ss.; en el mismo sentido la sentencia posterior del 5 de febrero de 1987, en Ley y jurisdicción extranjera en contratos de empréstito externo, Bogotá, Banco de la República, 1987, pp. 194 ss.

50 Este argumento fué resaltado por el magistrado Gustavo Gómez Velásquez, quien en su salvamento de voto criticó los términos de negociación de la deuda externa en general, Foro Colombiano, t. XXXVI, 1987, pp. 62 ss., 65. En sentido positivo ver los comentarios de Leavy, James, "Colombian Supreme Court Saves Foreign Loans", International Financial Law Review, Feb. 1987, p. 47; Linares Cantillo, supra nota 39, pp. 129 ss., con la confesión algo resignada, p. 136: "La verdad es que la realidad económica de los mercados internacionales de capitales no permite al gobierno nacional ejercer sus prerrogatives para asegurar la supremacía del interés público en los préstamos externos."

51 Cf. Wesley, Roger C., "The Procedural Malaise of Foreign Investment Disputes in Latin America: From Local Tribunals to Factfinding", Law and Policy in International Business, Washington, vol. VII, 1975, pp. 813 ss., 850 n.199. Ver también Germany G., María Cristina, y Sierra C., Enrique, "La renegociación de los servicios de la deuda externa de 1972“, Boletín Mensual, Banco Central de Chile, año XLVI, 1973, pp. 245 ss., 254. 
Decreto-Ley 2349 de 1978 de la Junta, firmado por el general Augusto Pinochet, dice en su art. 1:

"Decláranse válidos los pactos destinados a sujetar al derecho extranjero los contratos internacionales, cuyo objeto principal diga relación con negocios u operaciones de carácter económico o financiero, celebrados o que se celebren por organismos, instituciones o empresas internacionales o extranjeras que tengan el centro principal de sus negocios en el extranjero, con el Estado de Chile o sus organismos, instituciones o empresas.

Son igualmente válidas las estipulaciones por las cuales se haya sometido o se sometan diferendos derivados de tales contratos a la jurisdicción de tribunales extranjeros, incluyendo tribunales arbitrales previstos en mecanismos de arbitraje preestablecidos o en el respectivo contrato, como también las estipulaciones por las que se haya fijado o se fije domicilio especial y se haya designado o se designe mandatario en el extranjero para los efectos del contrato.

Lo dispuesto en los incisos anteriores igualmente es aplicable a los actos y contratos por los cuales el Estado de Chile o sus organismos, instituciones y empresas, hayan otorgado u otorguen en cualquier forma, su garantía a terceros en los contratos a que se refiere el inciso primero.

En virtud del sometimiento a la jurisdicción de un tribunal extranjero, cesará el derecho a invocar la inmunidad de jurisdicción, a menos de estipulación expresa en contrario."

El Decreto 1009 del mismo año contiene una enumeración global de las entidades estatales que están autorizadas a pactar en los términos del Decreto-Ley 2349. Desde entonces, esta autorización ha sido religiosamente prolongada año por año, ${ }^{52}$ hasta que la autorización expresa fué declarada inecesaria para ciertos contratos y operaciones en el mercado financiero internacional. ${ }^{53}$ Según parece, no se ha manifestado, en contra de estas normas legales, ningún comentario crítico en la doctrina y práctica chilenas.

\section{Ecuador}

En el Ecuador, la doctrina Calvo tiene rango constitucional. Así la Constitución de 1945, que fué reintroducida en 1972, disponía que "en los contratos que en el Ecuador celebraren los extranjeros con el Gobierno o con entidades de Derecho Público, no se podrá convenir la sujeción a una jurisdicción extraña $"{ }^{54}$ No obstante, en varias oportunidades, el Gobierno ecuatoriano ha aceptado la cláusula arbitral en contratos de préstamos internacionales. ${ }^{55}$ Para esto se aprovechó del argumento algo sofisticado de que el precepto constitucional sólo prohibía la declinación de la jurisdicción nacional si el contrato se suscribía "en el Ecuador", ${ }^{56}$ lo que no era del caso en este tipo de contratación. Con todo,

52 Ver Decreto 1009 del 13/12/1978; Decreto 1104 del 10/12/1979; Decreto 946 del 2/12/1980; Decreto 869 del 1/12/1981; Decreto 857 del 17/11/1982; Decreto 840 del 14/11/1983; Decreto 1039 del 20/12/1984; Decreto 1096 del 9/12/1985; Decreto 930 del 2/12/1986.

53 Ley 18233 de 1983, art. 4 inc. 2; Ley 18375 de 1984, art. 2 inc. 2; Ley 18442 de 1985, art. 3 inc. 2; cf. también la Ley 18550 de 1986.

54 Art. 153 inc.2; en las Constituciones de 1946 y 1967 faltaba una norma similar.

55 Jimenez Salazar, Carlos, "National Report: Ecuador", Yearbook Commercial Arbitration, Deventer, Kluwer, vol. III, 1978, pp. 76 ss., 77.

56 Ibidem, p. 79. 
ante las críticas en contra de esta interpretación, la reforma constitucional de 1978 ha modificado expresamente el texto de la norma en cuestión, que ahora es el siguiente:

"Los contratos celebrados por el Gobierno o por entidades públicas con personas naturales o jurídicas extranjeras, llevarán implícita la renuncia a toda reclamación diplomática; si tales contratos fueren celebrados en el territorio de Ecuador, no se podrá convenir la sujeción a una jurisdicción extraña". ${ }^{57}$

De tal manera, ha quedado muy fácil burlar el precepto constitucional, celebrando el contrato fuera del país. ${ }^{58}$ En la práctica, basta la autorización a un funcionario del Ministro de Finanzas y Crédito Público, para que él suscriba el contrato de crédito en el extranjero. ${ }^{59}$

\section{México}

México siempre ha seguido una posición pragmática. Por un lado, la doctrina Calvo fué aquí expresamente corroborada por la doctrina Carranza, y no faltan las voces que defienden estos principios especialmente en relación con los problemas de la deuda externa. ${ }^{60}$ Por otro lado, el propio Estado mexicano se ha sometido sin escrúpulos a la ley y jurisdicción extranjera en los contratos de crédito externo, si el lugar del pago y reembolso contractual estaba situado fuera del país. ${ }^{61}$ Así en el año 1983, en la reestructuración de la deuda mexicana con la banca internacional, se ha pactado la aplicación de la ley de Nueva York, la renuncia a la inmunidad y, a elección de los acreedores, la jurisdicción de los tribunales de Nueva York, de Londres, de México y de la sede principal de cada banco en particular. ${ }^{62}$

Sin embargo, la validez de estas cláusulas en el Derecho mexicano es dudosa. Primero, la autonomía de las partes para elegir la ley aplicable en la negociación contractual, no está claramente definida en la doctrina y práctica mexicanas. ${ }^{63}$ Segundo, realmente no se

57 Art. 16 de la Constitución de 1978, en la redacción por la Ley Reformatoria de 1983; ver el texto vigente en Registro Oficial, núm. 763, del 12 de junio de 1984.

58 En este sentido la crítica de Larrea Holguín, Juan, "La nueva Constitución de Ecuador", Estudios de Derecho, Universidad de Antioquia, Medellín, vol. XXXVIII, 1979, pp. 431 ss., 442.

59 Ver p.ej. el Decreto 3585-A de 1987, Registro Oficial, núm. 840, del 28 de diciembre de 1987.

60 Cf. en general Casillas Vélez, "La soberanía de los Estados y el Fondo Monetario Internacional", Revista de Investigaciones Juridicas, Escuela Libre de Derecho, México, núm.10, 1986, pp. 169-180, citando art. 27 de la Constitución; sobre otros problemas constitucionales en relación con la deuda externa mexicana ver Vázquez Pando, supra nota 4, pp. 175 ss.

61 Cf. Ritch, James E., "Legal Aspects of Lending to Mexican Borrowers", The North Carolina Journal of International Law and Commercial Regulation, vol. VII, 1982, pp. 315, 318 ss., 324; Leavy, supra nota 6, p. 34; sobre cláusulas arbitrales en préstamos internacionales ver Briseño Sierra, Humberto, "National Report: Mexico", Yearbook Commercial Arbitration, vol. III, 1978, pp. 94 ss., 97.

62 Ver Vázquez Pando, supra nota 4, pp. 200 s.; más general sobre la renegociación Stoakes, Christopher F., y Wilson, Chase deKay, "The Deals of 1983", International Financial Law Review, Jan. 1984, pp. $9 \mathrm{~s}$.

63 Sobre la respectiva cláusula del convenio de 1983 véase, en sentido negativo, Camil, Jorge, "The Nationalized Banking System and Foreign Debt", The International Lawyer, vol. XVIII, 1984, pp. 323 ss., 328; además 
sabe cuál es la autoridad mexicana competente para renunciar a la inmunidad del Estado. ${ }^{64}$ Finalmente, las cláusulas de jurisdicción en el contrato de 1983, que obran de modo unilateral en favor de los bancos, han sido calificadas de "abusivas" por un renombrado jurista mexicano. ${ }^{65} \mathrm{Al}$ parecer, sin embargo, cuando se incluyeron las mismas cláusulas en los más recientes contratos de renegociación en 1985 y 1987, no se presentó ninguno de estos argumentos por parte de México. ${ }^{66}$

\section{Perú}

La Constitución peruana de 1936, como una reacción a los eventos en el caso de La Brea y Pariña, consignó la doctrina Calvo en su art. 17, exigiendo la sumisión a las leyes y tribunales de la República en todo contrato del Estado con extranjeros ${ }^{67}$ Esta norma fué rigurosamente aplicada también en los contratos que celebraron las empresas públicas peruanas. ${ }^{68}$ Sin embargo, con el tiempo tal posición nacionalista fué considerada un obstáculo para la creciente participación del Perú en el mercado comercial y financiero internacional. ${ }^{69}$ Parece que, ya en los comienzos de los años setenta, ante la urgencia del crédito externo, se firmaron contratos de empréstito en el extranjero que no cumplieron con el precepto constitutional, recurriéndose al argumento de que el art. 17 sólo regía

Corse, C. Thorne, "International Term Loan Agreements and Loan Sindications", The Journal of Commercial Bank Lending, Philadelphia, March 1978, pp. 12 ss., 13; Bayitch, S.A., y Siqueiros, José Luis, Conflict of Laws: Mexico and the United States, University of Miami Press, 1968, pp. 135 ss.; Ritch, supra nota 61, pp. 320 ss.; Quale, supra nota 26, p. 293; en favor de la autonomía de las partes Vázquez Pando, supra nota 4, p. 207 n.232; con salvedades también Pereznieto Castro, Leonel, "Las obligaciones convencionales en el Derecho internacional privado mexicano", El Foro, México, Colegio de Abogados, Sexta época, núm.6, 1976, pp. 43 ss., 48 ss.

64 Cf. Vázquez Pando, supra nota 4, p. 206.

65 IDEM, pp. 206 s. En el mismo sentido ahora el art. 567 del Código Federal de Procedimientos Civiles, reformado por Decreto del Congreso del 11 de diciembre de 1987, Diario Oficial del 12 de enero de 1988, p. 9.

66 Sobre el Convenio de Reestructuración del 20 de marzo de 1987 ver Siqueiros, José Luis, "Deuda pública externa, Aspectos jurídicos de una posible moratoria ", Jurídica, Anuario del Departamento de Derecho de la Universidad Iberoamericana, México, núm. 18, 1986-87, pp. 573 ss., 583 s.; sobre las renegociaciones anteriores Castro Tapia, Enrique, "Mexico's Debt Restructuring: The Evolving Solution", Columbia Journal of Transnational Law, New York, vol. XXIII, 1984/85, pp. 1-9; Sander, Alison B., "International Debt: IMF-Mexico Stand-By Agreement ", Harvard International Law Journal, vol. XXVIII, 1987, pp. 157-165; Vázquez Pando, supra nota 4, pp. 215-218; generalmente Suárez Dávila, Francisco, "La crisis de la deuda externa y el desarollo", Comercio Exterior, México, Banco Nacional de Comercio Exterior, vol. XXXVI, 1986, pp. 1109-1113.

67 Cf. Rubio, Marcial, "Sujeción a los tribunales y leyes peruanos en los contratos del Estado con extranjeros", Apuntes, Lima, Universidad del Pacífico, año II, núm.3, 1974, pp. 115-130; para el trasfondo histórico ver Castañeda, Jorge Eugenio, "Análisis del Laudo que pretendió poner término a la controversia sobre 'La Brea y Pariñası ", Revista de Derecho y Ciencias Politicas, Lima, Universidad Nacional Mayor de San Marcos, año XXVIII, 1964, pp. 5-24.

68 Ver p.ej. el contrato de Petroperú con Occidental Petroleum Corp. del 22 de junio de 1971, citado por Cárdenas, Emilio J., "Nuevas características del marco jurídico de la explotación de los recursos naturales en el contexto latinoamericano", Derecho de la Integración, Buenos Aires, Banco Interamericano de Desarollo, INTAL, núm. 22/23, 1976, pp. 67 ss., 70 ss., 72 s.

69 Mac Lean U., Roberto, "El Derecho internacional privado y la Constitución ", Revista de Derecho y Ciencias Politicas, vol. XLIII, 1979, pp. 59, 73 ss.; IDEM, Derecho de comercio internacional, Lima, 1980, pp. 43 ss. 
dentro del territorio de la República. ${ }^{70}$ Después, ganaron gran notoriedad los contratos sobre el Oleoducto Nor-Peruano, firmados en Tokyo en 1974, sometidos en la parte de los préstamos a la ley y jurisdicción japonesas, en la parte de la compra-venta a la ley y arbitraje inglesas. ${ }^{71}$ Estos contratos se basaron en dos Decretos-Leyes del año 1973, que habían expresamente autorizado las empresas públicas a adaptarse en sus operaciones a la "práctica internacional", siendo el alcance y la validez de estas normas muy controvertidos. $^{72}$

Con la Constitución de 1979, la materia ha hallado una nueva regulación, que, por un . lado, extiende la doctrina Calvo claramente a las empresas públicas, y, por otro lado, prevé dos excepciones para el sector financiero y lo establecido en tratados internacionales. Dice ahora el art. 136 de la Constitución:

"Las empresas extranjeras domiciliadas en el Perú están su jetas sin restricciones a las leyes de la República. En todo contrato que con extranjeros celebran el Estado o las personas de derecho público o en las concesiones que se les otorgan, debe constar el sometimiento expreso de aquéllos a las leyes y tribunales de la República y su renuncia a toda reclamación diplomatica.

Pueden ser exceptuados de la jurisdicción nacional los contratos de carácter financiero.

El Estado y las personas de derecho público pueden someter las controversias derivadas de contratos con extranjeros a tribunales judiciales o arbitrales constituidos en virtud de convenios internacionales de los cuales es parte el Perú."

Pero esta norma no ha puesto fin al las controversias, dejando abiertas las siguientes cuestiones: ¿El inciso 1 ha derogado definitivamente las autorizaciones dadas por los mencionados Decretos-Leyes de $1973 ?^{73}$ El inciso 2 - especialmente discutido en relación con los contratos de refinanciación - al admitir la sumisión a una jurisdicción extranjera, ¿también autoriza la aplicación de la ley extranjera y la renuncia a la inmunidad? ${ }^{74}$ ¿El

70 Rubio, supra nota 67 , p. 124; similarmente en otras áreas del comercio internacional, según Norberg, Charles R., "Inter-American Commercial Arbitration Revisited ", Lawyer of the Americas, University of Miami, vol. VII, 1975, pp. 275 ss., 279; ver también Aramburú Menchaca, Andrés A., "El arbitraje comercial en el Perú “, Revista de Jurisprudencia Peruana, Lima, año XXXVII, 1978, pp. 456 ss., 462.

71 Partes en los contratos del 28 de agosto de 1974 eran por un lado Petroperú y Corporación Financiera de Desarollo, por otro lado Japan Petroleum Development Corporation y Japan-Peru Oil Co.; ver el texto completo en International Legal Materials, Washington, vol. XV, 1976, pp. 1295-1342.

72 Decreto-Ley 19988 del 13 de abril de 1973 y Decreto-Ley 20050 del 5 de junio de 1973, en Normas Legales, Trujillo, t. LXVII, 1973, pp. 51 y 315; ver la discusión en Rubio, supra nota 67, pp. 126 ss.; Quale, supra nota 26, pp. 292 s., 300; Mac Lean, supra nota 69, pp. 74 s. respectivamente pp. 45 ss.

73 Lo niega Mac Lean, Derecho de comercio internacional, supra nota 69, p. 48, quien defiende la tesis de "que la interpretación dada por los Decretos Leyes 19988 y 20050 es la interpretación que ha predominado en el texto de la nueva Constitución."

74 Est o se discute en el Informe "La legalidad de los contratos de refinanciación de la deuda externa", elaborado por encargo de miembros del Congreso, en Revista del Foro, Colegio de Abogados de Lima, año LXXI, 1984, núm.1, pp. 71 ss., 79 ss. La sumisión a la ley extranjera es admitida expresamente por la Segunda Disposición Complementaria de la Ley General de Endeudamiento Público Externo, Decreto Legislativo No.5 del 30 de diciembre de 1980, Normas Legales, t. CV, 1980, pp. 270 ss.; en torno a esta norma ver la discusión en Actualidad Económica del Perú, Lima, núm. 88, 1987, pp. 6 ss. Más detalladamente Zuñiga Paz, Augusto, "La deuda pública externa: Aspectos económicos y jurídicos", en Deuda externa, Problemas y soluciones, Lima, 1985, pp. 99 ss., 144 ss., sobre los contratos de refinanciación de 1983. 
inciso 3 sólo alude a tribunales judiciales y arbitrales creados por tratado ${ }^{75} \mathrm{o}$ abarca p.ej. un arbitraje fundado en la Convención de Nueva York, recientemente ratificada por el Perú ${ }^{76}$ Hasta ahora no se ha formulado un criterio definido sobre estos interrogantes en la doctrina y práctica peruanas.

\section{Venezuela}

En Venezuela la doctrina Calvo fué sancionada por primera vez en la Constitución de 1893, debido a reclamaciones diplomáticas por deudas que el Estado venezolano había asumido frente a acreedores extranjeros. ${ }^{77}$ Es interesante notar que fueron estos mismos hechos los que después llevaron al bloqueo de los puertos venezolanos por las potencias europeas, de donde se originó la llamada doctrina Drago. ${ }^{78}$ Desde entonces, todas las Constituciones venezolanas han incluido una norma similar hasta el art. 127 de la Constitución vigente de 1961, cuyo tenor es el siguiente:

"En los contratos de interés público, si no fuere improcedente de acuerdo con la naturaleza de los mismos, se considerará incorporada, aun cuando no estuviere expresa, una cláusula según la cual las dudas y controversias que puedan suscitarse sobre dichos contratos y que no llegaren a ser resueltas amigablemente por las partes contratantes serán decididas por los Tribunales competentes de la República, en conformidad con sus leyes, sin que por ningún motivo ni causa puedan dar origen a reclamaciones extranjeras."

A base de este precepto constitucional, el Gobierno venezolano por mucho tiempo ha defendido la posición de que toda sumisión a una ley y jurisdicción extranjeras en un contrato de empréstito, celebrado por la República o sus entidades estatales, sería nula. Pero esta actitud se ha flexibilizado en los años setenta ante la necesidad del crédito externo. La Procuraduría General de la República en diferentes oportunidades se ha pronunciado sobre el asunto, llegando a opiniones contradictorias, debido a los cambios de la administración. Finalmente, en las más recientes renegociaciones de la deuda externa, el Gobierno venezolano ha abandonado su posición anterior, valiéndose del argumento de que los contratos de préstamo son de naturaleza comercial y por eso están

75 Como el Tribunal Andino o el Centro del Banco Mundial; cf. Mac Lean, "El Derecho internacional ...", supra nota 69, p. 77; Aramburú Menchaca, Andrés A., "International Commercial Arbitration in the Andean Pact", en The Art of Arbitration, Liber amicorum Pieter Sanders, Deventer, Kluwer, 1982, pp. 27 ss., 31 n. 3.

76 Resolución Suprema 24810 del 24 de mayo de 1988, El Peruano del 25 de mayo de 1988. Sobre cláusulas arbitrales pactadas por el gobierno peruano ver Lliteras, Juan Andrés, "El arbitraje internacional entre Estados y particulares", Comparative Juridical Review, Coral Gables, Florida, vol. XX, 1983, pp. 111 ss., 115; cf. también Decreto Supremo 502-84-EFC del 23 de noviembre de 1984, Normas Legales, t. CXXXI, 1984, pp. 99 s., en relación con un contrato de préstamo entre Perú y el Kreditanstalt für Wiederaufbau de la República Federal de Alemania.

77 Art. 149 de la Constitución de 1893; cf. sobre esto Oropeza, Ambrosio, La nueva Constitución venezolana 1961, Caracas, 1971, pp. $381 \mathrm{~s}$.

78 Supra nota 7. 
exceptuados de la regla del art. $127 .{ }^{79}$ Este cambio de posición tal vez pueda basarse en el nuevo art. 58 de la Ley Orgánica del Crédito Público, agregado en 1983, que autoriza al Gobierno a negociar la refinanciación de la deuda pública "dentro de las condiciones existentes en los mercados financieros internacionales $"{ }^{80}$ Pero no corresponde de ningún modo al origen histórico del precepto constitucional.

\section{Observaciones finales}

El mundo financiero internacional es un sistema complejo. En este estudio nos hemos limitado a tratar la deuda externa del sector público con los bancos comerciales extranjeros. Sin embargo, la deuda externa la constituyen también, por un lado, los créditos entre empresas o personas privadas, $y^{\circ}$, por otro lado, los convenios financieros entre los gobiernos o los préstamos otorgados por organismos públicos internacionales o extranjeros, para los cuales sería necesario un estudio separado. ${ }^{81}$ Pero estos segmentos de la deuda externa sólo en teoría pueden distinguirse tan nítidamente, porque en realidad hay varios modos de conexión, como se ve también en las negociaciones sobre la refinanciación. Para dar una solución justa a los asuntos que hemos tratado anteriormente, sería necesario un análisis de cada caso en particular. No obstante, debemos limitarnos a presentar a continuación algunas conclusiones generalizadas y simplificadas.

\section{La invalidez de las cláusulas impuestas}

En resumen, la situación actual en la negociación de la deuda pública externa en América Latina puede describirse como un triunfo de los acreedores sobre la doctrina Calvo, la cual todavía vive en otros campos de la contratación estatal. Una legislación especial para el campo financiero ha creado las condiciones para que los créditos externos pueden ser exceptuados de la jurisdicción y legislación de los Estados deudores, a pesar de mucha resistencia en el área política. En años anteriores, la aceptación o no de la doctrina Calvo por los bancos extranjeros ha sido una parte de la valoración del riesgo. ${ }^{82}$

79 Sobre las variaciones de la posición venezolana ver Quale, supra nota 26, pp. 293 s., refiriéndose al discurso nacionalista del presidente Herrera Campins de septiembre de 1979, publicado en el Diario de Caracas del 7 de noviembre de 1979, pp. 16 s.; además Hughes, Thomas L., "Venezuela's Restructuring and 1981 Law", International Financial Law Review, Sept. 1983, pp. 9, 11 s.; Leavy, supra nota 6, p. 34.

80 Ley de Reforma Parcial de la Ley Orgánica del Crédito Público, promulgada el 22 de agosto de 1983, Gaceta Oficial, núm. 3253 extraordinario, del 14 de setiembre de 1983. Sobre los motivos de esta reforma ver Hughes, supra nota 79 , pp. $10 \mathrm{~s}$.

81 Ver Ojeda Marin, supra nota 14, pp. 127 ss., 146 ss., 193; Vázquez Pando, supra nota 4, pp. 173 ss., 190 ss.; Zimbler, supra nota 27, p. 513; Caicedo Castilla, supra nota 37, pp. 201 ss.; Leavy, supra nota 47, p. 7.

82 Sobre los criterios de esta valoración ver Quale, supra nota 26, pp. 290 ss., 300 ss.; cf. también Corse, supra nota 63, p. 14. 
Hoy, por una práctica constante, ellos suelen exigir que estos contratos cautelosamente redactados se sujeten a la jurisdicción y leyes de sus propios países, porque no hay otra salida para los Estados deudores.

Pero esta casi uniformidad despierta la duda de si no falta aquí el fundamento que únicamente pueda dar validez a las cláusulas contractuales: la libre voluntad de las partes contratantes. El principio universalmente aceptado pacta sunt servanda se basa en el supuesto de que las partes están en iguales condiciones para determinar libremente el contenido del contrato ${ }^{83}$ Consecuentemente, donde falta este equilibrio, se puede defender la tesis de que todas la cláusulas onerosas impuestas unilateralmente por una de las partes son inválidas. Así, puede haber casos en los cuales las cláusulas de jurisdicción y legislación aplicable resultan de una verdadera negociación entre las partes. ${ }^{84}$ Pero donde no hay libertad negociadora, una demanda basada en estas cláusulas podría correr el riesgo de ser rechazada por tratarse de cláusulas abusivas, establecidas sólo en favor de una parte, o aun de un forum non conveniens. ${ }^{85}$ La práctica cautelar ya ha tomado en consideración este argumento, exigiendo una renuncia expresa del deudor a tales excepciones. ${ }^{86}$ Además, la banca internacional ha logrado una reforma legislativa en el Estado de Nueva York que reduce allí la aplicación de la teoría del forum non conveniens al mínimo. ${ }^{87}$

Pero también en el caso de que el acreedor gane el proceso en el foro contractual, los ef ectos de una tal sentencia están limitados a los bienes que el Estado deudor tiene dentro de esta jurisdicción. Ya en terceros Estados, donde el acreedor quiere ejecutar la sentencia, puede ser confrontado de nuevo con el argumento de la incompetencia del

83 Cf. Mestmäcker, Ernst-Joachim, "Uber die normative Kraft privatrechtlicher Verträge", Juristenzeitung, Tübingen, año XIX, 1964, pp. 441-446.

84 Ver p.ej. los contratos de construcción y financiamiento entre la República Dominicana y un conjunto de bancos y empresas extranjeros para el proyecto termoeléctrico Itabo II, Gaceta Oficial, 1986, pp. 376-502, donde el contrato de construcción quedó su jeto a la legislación dominicana, los contratos de financiamiento a diferentes legislaciones extranjeras.

85 Cf. para las "cláusulas abusivas" Vázquez Pando, supra nota 8 y 65; también el Informe, supra nota 74, p. 80. Sobre la "inconveniencia" del foro contractual ver Gruson, Michael, "Controlling Site of Litigation", en Sovereign Lending . .., supra nota 2, pp. 29, 36-39, citando a Kline v. Kawai America Corp., 498 F. Supp. 868,872 (D. Minn. 1980): "Thus, the inconvenience factor is tied to the final factor, whether the clause was equally bargained for."

86 Modelo en Wood, supra nota 3, p.87: "The Borrower hereby irrevocably waives any claim that it may have that any such legal proceedings have been brought in an inconvenient forum "; cf. también Cates, Armel C., y Isern-Feliu, Santiago, "Governing Law and Jurisdiction Clauses in Euroloan Agreements", International Financial Law Review, July 1983, pp. 28, 31-33. Otras cláusulas someten la validez de la elección del foro a la propia ley del contrato; ver p.ej. el Convenio de Préstamo, celebrado por Honduras con un banco suizo, en $L a$ Gaceta, núm. 24.779, del 22 de noviembre de 1985, art. 14.

87 Cf. Gruson, supra nota 85, p.50. La nueva ley de 1984 ya se aplicó en el caso de un banco venezolano que había renunciado a "any right which it may now or hereafter have under the Laws of the Republic of Venezuela to have any action or proceeding ... brought only before a court or tribunal in the Republic of Venezuela"; Crédit Français International, S.A. v. Sociedad Financiera de Comercio, C.A., 490 N.Y.S. 2d 670, 678 s. (1985). Ver más detalladamente sobre esta reforma Ebenroth, Carsten-Thomas, y Tzeschlok, Regina, "Rechtswahlklauseln in internationalen Finanzierungsverträgen nach New Yorker Recht", Praxis des Internationalen Privat- und Verfahrensrechts, Bielefeld, Gieseking, año VIII, 1988, pp. 197, 199 ss. 
foro convenido de donde proviene aquélla. Y una ejecución en el propio Estado deudor no sólo tropezaría con la excepción del orden público, sino también con las varias limitaciones de una ejecución en los bienes del Estado. ${ }^{88}$ Por consiguiente, parece que una sentencia pronunciada en el país del acreedor en estas condiciones tiene primordialmente fines políticos: sirve para presionar al Estado deudor y es por esto por lo que los acreedores insisten en incluir estas cláusulas en sus contratos.

\section{2. "Forum rei" y ley del Estado deudor}

Si aceptamos la idea de que las mencionadas cláusulas contractuales pueden ser invalidadas por abusivas, la jurisdicción de los tribunales en cada caso tendrá que ser aceptada o denegada según las reglas generales de competencia, que varían de país a país. Un criterio universalmente reconocido en esta materia es el adagio forum rei sequitur, de cuya aplicación resulta aquí que el Estado deudor debe ser demandado ante sus propios tribunales. No valdrá el argumento de que el acreedor puede desconfiar de la neutralidad de este foro, sin que con eso al mismo tiempo quedaría justificado el recelo que tienen viceversa los países deudores en contra de los tribunales extranjeros. ${ }^{89}$ Evidentemente, los bancos prefieren la justicia de su propio país, porque están familiarizados con ella y tienen todas sus facilidades prácticas allí. Pero, de hecho, en las cláusulas de jurisdicción que ellos utilizan para sus contratos de préstamo, siempre suelen reservarse el derecho que pueden accionar también ante los tribunales del Estado deudor, lo que muestra que su desconfianza no es insuperable.

Esas mismas preguntas se ponen en relación con la ley aplicable, una vez invalidada la cláusula que designa la ley del país del acreedor. Hay que buscar una conexión objetiva para el contrato conforme a las reglas del Derecho internacional privado que se aplican en el país del foro. No es posible aquí entrar en detalles.$^{90}$ En muchos países el contrato de préstamo se sujeta a la ley del domicilio del banco, lo que equivale a atribuir fuerza

88 Ver en general Quale, supra nota 26, pp. 302 s., 305 s., 312 s.; en Argentina el reciente Decreto 679 del 26 de mayo de 1988 (B.O. 7/6/88); para Brasil Zimbler, supra nota 27, pp. 530 ss., 538 ss., 552 ss.; para Colombia Leavy, James, "Council of State Decision Causes Concern", International Financial Law Review, Febr. 1988, p. 48; para México Vázquez Pando, supra nota 4, pp. 206 s., 223 ss.; Siqueiros, supra nota 66, p. 585; para Perú el editorial "Bringing it All Back Home", International Financial Law Review, April 1986, p.2, y el comentario ibidem, May 1986, p.4. Sobre los efectos negativos de un embargo de los bienes del Estado deudor situados en el extranjero véase Skuhersky, Vera S., "Legal Aspects of the Latin American External Debt and Its Ramifications for the Development and Integration of the Americas", The University of Miami Inter-American Law Review, vol. XVI, 1984/85, pp. 109 ss., 120 ss.

89 Cf. Quale, supra nota 26, p. 302 ss., quien glosa "the natural tendency to believe that one's own courts are objective and free from influence whereas the other's courts are biased and subject to manipulation " (303). Más explícitamente en Colombia el magistrado Gómez Velásquez, supra nota 50, p. 65, denunciando muna mutua deconfianza: los países en vía de desarollo dudan tanto de la justicia foránea, en la definición de esta clase de asuntos económicos multinacionales, como los emprestadores, a su turno, de la justicia nacional del que recibe el empréstito."

90 Para un panorama general de los diferentes elementos de conexión en el Derecho comparado ver Rabel, Ernst, The Conflict of Laws: A Comparative Study, 2a ed., Ann Arbor, vol. III, 1964, pp. 3-16. 
normativa a la práctica contractual de los propios bancos. Lleva al mismo resultado la conexión al lugar de la celebración del contrato o al lugar del pago y reembolso, porque estos lugares se eligen arbitrariamente para coincidir con el domicilio de los bancos, como hemos señalado en relación con los intentos de burlar ciertas prohibiciones constitucionales de los países latinoamericanos. ${ }^{91}$ Sin embargo, frente a estas conexiones, hay argumentos válidos que militan en favor de la ley del propio Estado deudor, porque es en este Estado donde se necesita y utiliza el capital prestado. El interés legítimo del Estado soberano de sujetar sus obligaciones a su legislación interna ya fué reconocido en 1929 por la Corte permanente de Justicia internacional, en el caso de los empréstitos brasileños. ${ }^{92} \mathrm{Y}$ también los propios bancos respetan este interés, cuando el Estado contratante mantiene una fuerte posición negociadora. ${ }^{93}$

Contra la aplicación de la ley del Estado deudor se ha aducido que, con esto, el contrato de préstamo queda expuesto a los cambios legislativos y políticos dentro del propio Estado prestatario. Pero, este argumento sólo tiene valor relativo. Por un lado, tampoco el Derecho de los países creditores está libre de estas influencias políticas, como lo han mostrado las medidas del Gobierno de los EE.UU. durante la crisis iraní o del Gobierno británico en el conflicto de las Malvinas, medidas cuya aplicación ha ef ectado directamente al mercado financiero. ${ }^{94}$ Por otro lado, hay que subrayar el destacado lugar que tiene en el Derecho de los países latin̉oamericanos la doctrina de los derechos adquiridos, o sea el postulado de que una situación legalmente consolidada no puede ser afectada por un acto posterior del legislador..$^{95}$ Finalmente, no se debe olvidar que los actos monetarios y cambiarios de los Estados se rigen, según la doctrina moderna del Derecho internacional privado, por reglas especiales que de todas maneras se aplican independientemente de la ley del contrato. ${ }^{96}$

91 Supra, notas 30, 50, 55 s., 58 s., 70. El gobierno de Honduras en varios contratos de préstamo ha aceptado la legislación y jurisdicción del país "donde se suscriba este Convenio", firmándolo en el lugar de la sede del banco; ver La Gaceta, núm. 24.581, del 28 de marzo de 1985, p. 9, y núm. 24.780, del 23 de noviembre de 1985 , p. 10.

92 Sentencia del 12 de julio de 1929, C.P.J. Sér. A, nos. 20/21, pp. 91 ss., 121: ". . c'est, dans l'espèce, un État souverain, qui ne peut être présumé avoir soumis la substance de sa dette et la validité des engagements pris par lui à ce sujet à une loi autre que sa loi propre." Este argumento, aplicado por la Corte a un caso de bonos emitidos por el Estado, puede también servir de base para una regla especial de conflictos de leyes para los préstamos entre gobiernos y empresas privadas extranjeras; cf. García Calderón, Manuel, "Los conflictos de leyes y los préstamos internacionales", Revista del Foro, Lima, año L, 1963, núm 1-2, pp. 11 ss., $24=$ Revista del Ministerio de Justicia, Caracas, núm. 53, 1965, 389 ss., 406 s.

93 Ver los casos citados por Hinsch, supra nota 3, pp. 152, 154; Bosch, supra nota 9, p.124 n.12; Wood, supra nota 3 , p. 25.

94 Cf. Ojeda Marin, supra nota 14, pp. 190 ss.; Cates y Isern-Feliu, supra nota 86, p. 29. Los bancos suelen protegerse contra tales medidas de sus propios gobiernos por la llamada "illegality clause"; cf. Wood, supra nota 3, p. 143; Hinsch, supra nota 3, pp. 109 ss.

95 Ver Samtleben, Jürgen, Derecho internacional privado en América Latina, Buenos Aires, Depalma, vol. I, 1983, p. 258; Quale, supra nota 26, p. 295. Cf. sobre la jurisprudencia mexicana en relación a la conversión forzosa de los depósitos de dólares en bancos mexicanos Rendell, supra nota 12; Vázquez Pando, supra nota 4, p. 189.

96 Sobre las tendencias modernas en la materia, excepto en la jurisprudencia inglesa, ver Horn, Norbert, "Aktuelle Rechtsf ragen internationaler Konsortialkredite", Juristische Blätter, Wien, año CIX, 1987, pp. 409 
En el fondo, el verdadero riesgo para el acreedor no está en la aplicación de la ley del Estado deudor sino en el hecho de que éste, por razones económicas, se puede ver imposibilitado de cumplir con sus obligaciones financieras. En este caso, empero, también el Derecho internacional público reconoce su derecho a declarar una moratoria. ${ }^{97}$

\section{Soluciones alternativas}

Existe en general acuerdo en que el problema de la deuda externa no se puede resolver en términos de Derecho estricto. Por eso hay que buscar una fórmula que facilite a lo máximo posible una solución adecuada y flexible, y que evite la frustración que cada procedimiento judicial puede causar en las relaciones entre acreedores y Estados deudores. Por razones prácticas y psicológicas, ni los tribunales de una ni de otra parte pueden cumplir con esta función. En cambio, como ha señalado un jurista peruano, si las partes someten el contrato a la jurisdicción y legislación de un tercer país, esto puede ser considerado como un aspecto positivo y una mayor garantía de neutralidad, mitigando los recelos de las partes. ${ }^{98}$ Pero generalmente, los bancos comerciales de los países acreedores se aferran a la jurisdicción y legislación de sus propios Estados, porque una lagislación neutral no es considerada idónea para los contratos de préstamo. ${ }^{99}$

Otra solución posible sería la vía del arbitraje, como la incluyen los bancos internacionales y nacionales de desarrollo en sus contratos con los Estados prestatarios. El Banco Interamericano de Desarrollo, p.ej., prevé en sus contratos de préstamo un procedimiento arbitral "en conciencia", sin relación a legislación de país determinado. ${ }^{100}$ Sin embargo, en el mundo de la banca comercial tal procedimiento no se recomienda para los contratos financieros. ${ }^{101}$ Igualmente, en los países latinoamericanos tradicionalmente hay mu-

ss., 417, con especial referencia al art. VIII parag. 2 (b) del convenio de Bretton Woods. Esta norma ordena respetar las leyes cambiarias de los otros Estados contratantes, pero no impide la aplicación de semejantes medidas del propio Estado del foro, como parece insinuar la reciente decisión de la Corte Suprema argentina en el caso Citibank v. Narbaitz Hnos. y Cía., 17/9/1987, Jurisprudencia Argentina, t. 1987-IV, p. 713.

97 Cf. en detalle Vázquez Pando, supra nota 4, pp. 220 ss. Sobre las consecuencias legales y prácticas ver Siqueiros, supra nota 66, pp. 582 ss.; Albino, supra nota 34, pp. 22 s.; Horn, Norbert, "The Restructuring of International Loans and the International Debt Crisis", International Business Lawyer, IBA, London, 1984, pp. 400 ss., $406 \mathrm{~s}$.

98 Ver Ruiz-Elredge, Alberto, en Actualidad Económica del Perú, núm.86, 1987, p.9, con alusión a los contratos sobre el Oleoducto Nor-Peruano (supra, nota 71).

99 Wood, supra nota 3, p. 25. No es una excepción el contrato de préstamo entre Honduras y un banco danés (¿de capital norte-americano?), sometido a las leyes y tribunales de Nueva York; La Gaceta, núm. 25.329, del 28 de septiembre de 1987, p.5. Efectivamente, tal foro no se puede considerar neutral en este juego, como advierte Carty, Anthony, "The Third World Debt Crisis: Towards New International Standards for Contracts of Public Debt", Verfassung und Recht in Ubersee, Hamburg, año XIX, 1986, pp. 401 ss., 405.

100 Cf. el contrato tipo, Parte Primera, cláusula 8.03: "Los derechos y obligaciones establecidos en este Contrato son válidos y exigibles de conformidad con los términos en él convenidos, sin relación a legislación de país determinado." El procedimiento arbitral está regulado en la Parte Segunda, Capítulo IX, que prevé en caso de desacuerdo la designación del Dirimente por el Secretario General de la OEA.

101 Ver Ryan, Reade H., "Defaults and Remedies", en Sovereign Lending . ., supra nota 2, pp. 157 ss., 184 ss.; Wood, supra nota 3, pp. 71 ss.; Bosch, supra nota 9, pp. 136 s.; Ojeda Marin, supra nota 14, p. 178; Peralta, D. Javier, "Ley y jurisdicción aplicables", en Seminario . ., supra nota 14, pp. 73 ss., 90 s.; cf. 
cha resistencia en contra del arbitraje como forma de solucionar los conflictos, especialmente cuando el propio Estado se ve involucrado. Pero esta posición ya ha cambiado en los últimos tiempos. Como lo muestra el ejemplo del Brasil, un Estado puede preferir someterse más bien a un arbitraje internacional que a una jurisdicción extranjera, lo que en el caso de la renegociacíon de la deuda brasileña tambien fué tomado en cuenta por los bancos. ${ }^{102}$

Como el gran problema de la deuda externa, también la cuestión de cómo solucionar los conflictos jurídicos derivados de ella queda por ahora sin solución definitiva. En todo caso, es evidente que en ambos casos se debe buscar una solución conciliadora y equitativa. Si no se llega a una conciliación entre las partes, ¿cuál será la autoridad para imponer tal solución?

también Cates y Isern-Feliu, supra nota 86, pp. 34 s. En contra de esta opinión Pearce, Michael, "The Internationalisation' of Sovereign Loan Agreements", Journal of International Banking Law, Oxford, vol. I, 1986, pp. 165 ss., 174 s.; Meyer, supra nota 14, p. 110; ver además Sklar, supra nota 11, pp. 82 ss.

102 Ver supra, III 2. En el mismo sentido, en Argentina, la Procuración del Tesoro de la Nación en un dictamen del 13 de abril de 1983; cf. Dictámenes de la Procuración del Tesoro de la Nación, núm. 12, marzo de 1986, pp. 193 ss., 208 s. También la República Dominicana ha celebrado varios convenios de crédito con cláusula arbitral, pero sometidos a la legislación del país del banco extranjero; ver Colección de Leyes, Resoluciones, Decretos y Reglamentos, 1980, t. I, parte 1, pp. 56 ss., 72; 1980, t. I, parte 2, pp. 195 ss., 225; 1981, t. I, pp. 15 ss., 31; Gaceta Oficial, 1986, pp. 91 ss., 1007. Para los otros países ver supra. notas $55,61,76$. 
The article deals with the development, volume, structure and causes of the debt as well as the role of the public and private creditors since the beginning of the crisis. The analysis concludes that the dept burden is a decisive handicap in any effort to restore economic growth and to bring lasting improvements by structural adjustment.

\section{Lessons of the Latin American Debt Crisis}

\section{By Jürgen Westphalen}

The author's reflections begin with the admonition delivered by US Treasury Secretary James A. Baker: "We cannot afford to repeat the mistakes of the past!" Ten aspects of the Latin American debt crisis are used to illustrate misjudgments of specific situations and erroneous reactions of politicians in the early years of the crisis. According to the author, the major problem at present and in the future consists in the fact that on the one hand, the structural adjustment required in order to overcome the debt crisis can only be realized in the long term, while, on the other hand, the avoidance of serious socio-political effects of foreign debt calls for a marked alleviation of the crisis as soon as possible. The question of whether it will be possible for the debt crisis bo be overcome before the region suffers a relapse into dictatorship is regarded as open by the author.

Choice of Law and Forum Clauses in Public External Debt Agreements of Latin American States

\section{By Jürgen Samtleben}

Loan contracts and rescheduling agreements of Latin American states with foreign banks invariably include clauses on jurisdiction and applicable law. Recent events have shown the political and practical importance of such clauses, which usually stipulate the jurisdiction and the law of the bank's home country. The article discusses the validity of such clauses in the light of the Calvo doctrine, of Latin American legislation and of general principles of law. Most of these clauses must be considered unconscionable and therefore invalid. On the other hand, the banks wish to avoid suing the debtor state in its own courts. A solution might be to provide for a forum in a neutral state, or for an arbitral procedure ex aequo et bono regardless of the legislation of any given country, such as stipulated in the loan agreements of the Inter-American Development Bank. 